\title{
A participação dos atores na formulação da política de saúde da população negra na cidade de Salvador
}

| ${ }^{1}$ Marcos Vinícius Ribeiro de Araújo, ${ }^{2}$ Carmen Fontes Teixeira I

Resumo: Este artigo tem por objetivo

caracterizar os atores e analisar sua participação no processo de formulação da Política de Saúde da População Negra (PSPN) em Salvador-BA, Brasil, no anos 2005-2006. Foram realizadas revisão documental e entrevistas com informantes-chave e representantes de organizaçôes governamentais e não governamentais envolvidos no processo. Os resultados descrevem as características dos atores e analisam suas vinculações a organizações e trajetórias no Movimento Negro. Em seguida, discutem-se as formas de participação dos atores na pré-decisão e na decisão com respeito à PSPN, no processo de elaboração do Plano Municipal de Saúde 2006-2009. Conclui-se que o contexto político institucional no período estudado configurou uma "janela de oportunidade" para que um conjunto heterogêneo de atores, que tinham em comum a mobilização em torno da problemática da saúde da população negra, se articulasse no âmbito da Secretaria Municipal de Saúde e incluísse a problemática na agenda política de saúde do município, o que delineou em boa medida as características desse processo e de seus produtos.

> Palavras-chave: atores políticos; formulação de políticas de saúde; saúde da população negra.
1 Doutorando em Saúde

Coletiva e Mestre em Saúde Comunitária pelo Instituto de Saúde Coletiva da Universidade Federal da Bahia (UFBA).

Docente do Departamento de

Fonoaudiologia do Instituto

de Ciências da Saúde da

UFBA. Endereço eletrônico:

marvinribeiro@yahoo.com

2 Doutora em Saúde Pública pela UFBA. Professora do Bacharelado Interdisciplinar em Saúde e do curso de Mestrado do Programa de Estudos Interdisciplinares sobre Universidade, no Instituto de Humanidades, Artes e Ciências da Universidade Federal da Bahia. Docente do Programa de Pós-Graduação do Instituto de Saúde Coletiva da UFBA. Endereço eletrônico: carment@ ufba.br

Recebido em: 25/06/2012 Aprovado em: 13/01/2014 
A problemática da saúde da população negra no Brasil faz parte da herança histórica que relegou os negros, após a escravidão, a condições de existência marcadas pela pobreza e exclusão social (MUNANGA, 2004; GUIMARÃES, 2002). A emergência e o desenvolvimento das políticas sociais no Brasil, a partir da Primeira República, ignoraram essa situação, reforçando as relações raciais existentes no país, caracterizadas por racismo, intolerância e discriminação (LIMA et al., 2005; NOGUEIRA, 2001).

Essas características da sociedade e do Estado brasileiro acabaram por impor a luta contra o racismo e a discriminação social como questóes centrais para a ação política dos movimentos negros, cujas organizações foram formadas durante todo o século XX (DOMINGUES, 2007; GUIMARÃES, 2001; GONÇALVES, 1998). Uma das primeiras respostas positivas do Estado às reivindicações desses movimentos foi a criação do Conselho Estadual de Participação e Desenvolvimento da Comunidade Negra, em 1984, em São Paulo, cujo objetivo era elaborar e implementar políticas em benefício da população negra. A partir daí, várias experiências ocorreram em outros estados, com a criação de coordenadorias e "assessorias afro-brasileiras" em vários órgãos da gestão pública (JACCOUD; BEGHIN, 2002).

Assim, foram constituídos grupos técnicos vinculados, direta ou indiretamente, aos movimentos negros, que passaram a atuar no âmbito burocrático como sujeitos políticos, portadores das demandas, reivindicações e propostas nascidas nos movimentos. Essas iniciativas somaram-se aos esforços mais gerais de institucionalização dos direitos de cidadania, que confluíram para a aprovação de vários artigos da Constituição Federal de 1988, dentre os quais o que criminaliza o racismo.

A Marcha Zumbi dos Palmares, em novembro de 1995, expressou o acúmulo de conhecimentos e o grau de organização do Movimento Negro brasileiro, resultando em um documento contendo um diagnóstico sobre o racismo e um programa de açôes (GODINHO, 2009). No plano internacional, em 2001, a III Conferência Mundial contra o Racismo, a Discriminação Racial, a Xenofobia e Intolerâncias Correlatas, realizada em Durban, África do Sul, produziu um ambiente favorável à intensificação das mobilizaçōes por parte das organizações 
do Movimento Negro, principalmente as organizações de mulheres negras (BENTES, 2002; CARNEIRO, 2002; HERINGER, 2001).

Das ações iniciais centradas na denúncia da discriminação, o Movimento Negro passou as últimas décadas atuando na perspectiva "promocional", visando propiciar a inclusão social de grupos historicamente discriminados no acesso a determinados postos de trabalho, bem como no acesso à educação superior, através das "cotas", e, posteriormente, na expansão e qualificação da atenção à saúde (RABELO, 2008; HERINGER, 2000).

Nesse particular, o movimento da Reforma Sanitária, configurado pela mobilização de vários atores a partir da segunda metade dos anos 70 , colocou em debate as propostas de mudança na gestão e organização do sistema público de saúde, de modo a garantir universalidade, integralidade e equidade no acesso a ações e serviços. Na Constituição de 1988, foi incorporado ao capítulo "Saúde" esse conjunto de princípios e diretrizes, de modo que o Estado passou a assumir a responsabilidade pela construção do Sistema Único de Saúde (SUS), cuja implantação vem ocorrendo ao longo dos últimos 22 anos (PAIM, 2008).

A problemática específica da população negra, expressão maior das desigualdades sociais ainda prevalentes no país, entretanto, foi subordinada ao conjunto de políticas voltadas para a ampliação do acesso às ações e serviços de saúde, que não consideravam a desigualdade racial como elemento definidor das iniquidades (PNUD/OPAS, 2001). Durante a década de 90, essa questão veio a ser colocada explicitamente na agenda política governamental, tendo sido estabelecido o Grupo de Trabalho Interministerial de Valorização da População Negra, a partir do qual foi criado o subgrupo de saúde, em 1996, que passou a se responsabilizar pela elaboração e implantação de ações específicas nessa área, em particular o Programa de Anemia Falciforme (OLIVEIRA, 2000).

Em dezembro de 2003, na 12a Conferência Nacional de Saúde, a mobilização de diversas organizações do Movimento Negro conseguiu garantir a aprovação de cerca de 70 deliberações relacionadas, direta ou indiretamente, com a construção de estratégias de promoção da equidade de gênero, raça e saúde (BRASIL, 2005). No final do ano seguinte, o Ministério da Saúde aprovou o Plano Nacional de Saúde - Um Pacto pela Saúde no Brasil (PNS), no qual foi inserida a Saúde da População Negra, contemplando centralmente a anemia falciforme e a atenção às comunidades quilombolas (TANNUS; GOULART, 2007). 
É nesse contexto que emerge em Salvador, cidade com cerca de $80 \%$ da população afrodescendente, um conjunto heterogêneo de forças políticas, organizadas no espaço de religióes de matriz africana, entidades carnavalescas, movimentos e partidos políticos, implicadas e comprometidas com a problemática da população negra. Contando com uma conjuntura política local favorável, derivada da mudança ocorrida no governo municipal em 2005, os movimentos negros foram capazes de colocar a problemática da saúde da população negra e a promoção da equidade no acesso aos serviços de saúde na agenda política das Secretarias Municipais de Saúde e de Reparação. Este artigo tem como objetivo caracterizar os atores envolvidos nesse processo e analisar sua participação na formulação da Política Municipal de Saúde da População Negra, ocorrida no ano de 2005, como parte do processo de elaboração do Plano Municipal de Saúde.

\section{Marco teórico-conceitual: definindo os atores}

Para a construção do referencial teórico deste estudo, partimos da revisão da literatura sobre movimentos sociais (GOHN, 1997), distinguindo, em primeiro lugar, a identificação do "movimento negro", enquanto um movimento social organizado a partir da problemática racial, da categoria "ator social", que nos permite identificar e caracterizar as concepções e a natureza da ação política de pessoas e organizações envolvidas na apresentação de problemas e formulação de propostas no âmbito das relaçôes Estado-sociedade.

Nesse sentido, encontramos uma primeira aproximação da definição de atores políticos em Testa (1995), que os define como aqueles que carregam sobre seus ombros a responsabilidade de pôr em movimento as forças sociais, e os divide em duas categorias: atores individuais e coletivos. A primeira, formada por uma única pessoa, prevê um sujeito que tem interesses e que ocupa uma posição que o coloca em situação de peso dentro de determinado processo político. A segunda categoria, formada pelo agrupamento de sujeitos sociais individuais, configura o coletivo como ator na medida em que desenvolve ações que tendem à explicitação e defesa dos interesses coletivos, participando direta e/ou indiretamente de processos políticos que se desenvolvem em vários âmbitos, a exemplo do chamado "setor saúde".

Nessa mesma perspectiva, Debert (2004) define que os atores são experts, dotados de competência publicamente reconhecida, e ocupam uma posição 
privilegiada para tornar públicas as demandas que encampam. Constroem uma

identidade, assumem interesses diversos - de classe, corporativos, de grupos, individuais e até específicos (LINDBLON, 1985) -, podem transformar um determinado problema em objeto de luta política, adotam estratégias para garantir que suas reivindicações sejam incorporadas na agenda e gerem a formulação de políticas públicas (GERSCHMANN, 1989).

Nesse sentido, Kingdon (1984) explicita que os atores podem ser "governamentais" ou "não governamentais", os primeiros envolvendo os representantes dos poderes instituídos (Executivo, Legislativo, Judiciário) incluindo os servidores públicos, que compõem a burocracia estatal, e os segundos, constituídos por atores políticos que não ocupam posições na estrutura de poder formal do Estado, envolvendo grupos de interesse, especialistas, acadêmicos, partidos, a mídia e a opinião pública. A articulação desses atores gera "correntes", quais sejam, a "corrente do problema", a "corrente das alternativas de solução" e a "corrente da política", que atravessam o conjunto das organizações envolvidas no processo de formulação e implementação (CAPELA, 2007).

Com isso, podemos sintetizar que o ator constitui-se como uma resposta à existência de problemas, necessidades, interesses e demandas de determinados segmentos, presentes em determinados contextos, os quais estimulam sua organização e participação no processo político, que contempla desde a inclusão de um determinado tema na agenda até a formulação e a implementação de propostas de intervenção sobre problemas e o atendimento às necessidades. A configuração desse processo, portanto, depende da interação dos atores e da possibilidade de sua participação (desigual entre os envolvidos) em cada um dos seus momentos, desde a formação da opinião pública favorável em torno do tema, até a pressão política exercida pelos diversos atores para a inclusão de suas propostas no processo de formulação e implementação de ações.

\section{Metodologia}

A produção de informações foi feita entre agosto de 2008 e março de 2009, a partir de ampla revisão documental e realização de entrevistas com 14 informanteschave, que se envolveram, direta ou indiretamente, no processo de formulação da Política de Saúde da População Negra no município. 
A identificação desses informantes foi feita com base na recuperação da memória das integrantes do Grupo de Trabalho de Saúde da População Negra (GTSPN) da Secretaria Municipal de Saúde (SMS) de Salvador, segundo a técnica snowball (bola de neve). Ou seja, a partir da indicação inicial do GT foram sendo identificadas outras pessoas, até se configurar um conjunto considerado representativo dos atores que participaram do processo de inclusão da questão racial na agenda política do município. $\mathrm{O}$ conjunto das pessoas entrevistadas inclui tanto representantes das autoridades políticas nacionais e municipais envolvidas com a formulação da Política de Saúde da População Negra (PSPN) e da Política de Promoção da Igualdade Racial (PPIR), membros dos grupos e comitês técnicos da Secretaria Municipal de Saúde, bem como militantes do movimento negro e lideranças intelectuais que atuam na área.

Para a realização das entrevistas, foram elaborados dois roteiros com perguntas gerais e específicas que se diferenciavam de acordo com o perfil do informante-chave, isto é, se sua inserção era primariamente no processo de formulação da PSPN ou no processo de formulação da PPIR. Formulouse também um terceiro roteiro, dirigido ao GTSPN. As entrevistas foram gravadas, transcritas e analisadas visando: a) à caracterização de cada um dos atores identificados, levando-se em conta sua procedência e vinculação institucional a determinados movimentos e/ou grupos políticos e a identificação das formas e dos lugares onde o ator em questão desenvolve sua ação política; e b) à percepção dos atores acerca da sua participação na formulação da PSPN, tratando-se de identificar a forma como os atores se envolveram no estágio de "pré-decisão" (anterior à incorporação do tema na agenda governamental), e/ou no estágio de "decisão" (quando os diversos atores envolvidos analisaram e selecionaram as alternativas de enfrentamento dos problemas identificados e elaboraram as políticas propriamente ditas) (KINGDON, 1995). Na apresentação dos resultados, são identificados os documentos institucionais consultados, porém preserva-se o sigilo quanto à identidade dos entrevistados, nomeados por países africanos.

O estudo foi aprovado pelo Comitê de Ética em Pesquisa do Instituto de Saúde Coletiva da Universidade Federal da Bahia, e registrado sob o número 023-08. 


\section{Caracterização geral dos atores}

Os atores individuais possuem características bastante diversificadas. A maioria é composta por mulheres, afrodescendentes, na faixa etária de 40 a 60 anos. Em geral, possuem nível superior, sendo alguns pós-graduados, com formação profissional em áreas variadas: pedagogos, professores universitários, assistente social, sociólogos, nutricionista, economistas, enfermeira, sanitaristas, médicos, técnica em enfermagem, e técnico em manutenção. Também são diversas suas origens e atuações políticas: partidos políticos, organizações de luta antirracista, terreiros de candomblé, sindicatos, associações de bairros, órgãos de consultorias internacionais, associações de portadores de patologias, universidades, grupos culturais, etc.

No processo de formulação da política de Saúde da População Negra em Salvador, esses atores encontravam-se em lugares diferenciados (gestão municipal, órgãos de consultoria, associações, organizações populares, organização de luta antirracista, terreiros de candomblé), sendo que nem todos atuaram no seu local de origem. Alguns deles, embora com origem e trajetória em organizaçôes da sociedade civil, estavam naquele momento à frente de órgãos do governo municipal ou estadual, atuando também em nível nacional, junto a gestores do Governo Federal ou em movimentos articulados em redes nacionais.

\section{Atores não governamentais}

As entidades e organizações da sociedade civil envolvidas na formulação da PSPN têm se configurado em vários espaços, quais sejam os blocos afro, os terreiros de candomblé, o Movimento de Mulheres, grupos de hip hop, algumas associações de bairros e alguns partidos políticos, em geral de esquerda, segundo relatam os informantes (Congo, Benin, Nova Guiné, Angola).

Os blocos afro atuam enquanto entidades culturais, aglutinando segmentos da população negra do município em torno de questões relacionadas, em geral, com a afirmação da identidade cultural, o resgate das tradições africanas e a mobilização em torno da melhoria das condições de vida urbana. Incluem-se 
nesse grupo, segundo os entrevistados, os blocos Filhos de Gandhi, Ilê Aiyê, Malê de Balê, Muzenza e outros (Gana, Angola, Benin).

Dos terreiros, destacou-se a ACBANTU, Associação Cultural em Defesa do Patrimônio Bantu, que aglutina um conjunto de terreiros, a exemplo do terreiro Mokambu, cujo sacerdote e liderança comunitária (Benin) participou ativamente do processo de formulação da PSPN, representando a Rede de Religiōes Afrobrasileiras e Saúde (Benin, Gana).

A gente vem trabalhando dentro das casas de candomblé. Cada um dentro do seu portão. Só que a coisa foi crescendo, foi tomando outro rumo, foram aumentando. $\mathrm{E}$ as lutas foram solidificando [...]. [n] a minha vida, aconteceu entrar na Rede de Religiōes Afrobrasileiras de Saúde. Essa rede teve início em São Luís, no Maranhão, e vem percorrendo todo o Brasil, desde Pernambuco, João Pessoa, Rio Grande do Norte, Rio de Janeiro, São Paulo e enfim, Bahia; agora está indo para Manaus. (Benin)

Algumas mulheres do GTSPN, embora não representassem ou estivessem vinculadas diretamente a organizaçôes do Movimento de Mulheres Negras, revelam em suas entrevistas identidade com esse movimento, evidenciada na Articulação de Organizações de Mulheres Negras Brasileiras Pró-Durban, composta por mais de uma dezena de organizações de mulheres negras do país e coordenadas pelo Criola, organização de mulheres negras do Rio de Janeiro, pelo Geledés/Instituto da Mulher Negra, de São Paulo, e pelo Maria Mulher, do Rio Grande do Sul (BENTES, 2002).

As associações de bairros participaram por meio da FABS - Federação das Associações de Bairros de Salvador -, que agrega mais de 400 entidades comunitárias de Salvador, a exemplo das Associaçōes de Bairros do Nordeste de Amaralina, Engenho Velho de Brotas e Plataforma (Nova Guiné).

Além dessas organizações, destaca-se a Associação Baiana de Pessoas com Doença Falciforme (ABADFAL) e o Fórum de Combate à Violência, os quais, apesar de possuírem trajetórias diferenciadas, acumularam conhecimento e poder político durante o processo de formulação da PSPN, como se expressa, claramente, no discurso dos seus atores:

A ABADFAL lançou na Bahia o primeiro folder sobre anemia falciforme. Por mim e minha esposa. Ela, uma assistente social, e eu, um técnico em mecânica. (Gana)

Nós começamos no Fórum Comunitário Combate e Violência de 1997 no Nordeste de Amaralina [...]. [A] comunidade escolheu como problema prioritário de saúde a questão da violência, da violência policial [...]. A gente chegou à conclusão que para 
intervir na violência era preciso criar um Fórum Comunitário, uma articulação que

envolvesse a maior parte das associações, entidades, ONGs pra dar conta de enfrentar esse problema. (Nova Guiné)

À frente dessas organizaçōes constituíram-se verdadeiras lideranças, cidadãos comuns, que, diante dos problemas cotidianos e influenciados pelas ideias difundidas pelos movimentos, engajaram-se na formulação de propostas específicas na área de Saúde. Seja por meio de uma associação voltada às pessoas com patologia e seus familiares, seja através da articulação entre associações de bairros, grupos de pesquisa no seio de universidades, agências internacionais de fomento a pesquisas ou terreiros de candomblé, constituiu-se uma "corrente de política" (KINGDON, 1984), que se articulou em torno da ação políticoinstitucional do GTSPN criado na SMS.

\section{Atores governamentais}

No âmbito da gestão municipal, os atores que estavam à frente da SMS e da Secretaria Municipal da Reparação (SEMUR) e os que compunham o GTSPN também eram oriundos de algum tipo de organização da sociedade civil, o que, em certa medida, reflete a conjuntura política que levou o candidato João Henrique Carneiro à prefeitura de Salvador, contando com o apoio de uma ampla aliança partidária, entre os quais o PT e o PC do B. Esses partidos têm sido historicamente vinculados aos movimentos sociais em Salvador, inclusive a organizações do Movimento Negro, o que permitiu a indicação dos secretários da SMS e da SEMUR pelo PT, partido que já tinha incorporado a problemática racial em seu programa. Isso foi reforçado na entrevista do Secretário de Saúde, demonstrando a capilaridade do debate racial e a capacidade do Movimento Negro de inserir suas demandas na agenda de organizaçōes partidárias que formulam e disputam projetos no cenário político municipal, estadual e nacional.

$\mathrm{O}$ candidato que eu apoiei desde o primeiro turno, do Partido dos Trabalhadores (PT), incluiu no seu programa, na sua campanha a implantação de uma política de saúde para a população negra em geral e desigualdade racial, assim como o candidato que foi apoiado pelo meu partido $[\mathrm{PT}]$ no segundo turno, que acabou sendo eleito, João Henrique, na época do PDT... (Egito)

A indicação desse Secretário de Saúde contribuiu para a configuração do espaço institucional no âmbito da SMS que possibilitou a conformação do 
GTSPN, em torno do qual gravitaram os demais atores identificados. Esse grupo, composto logo no início da gestão, em fevereiro de 2005, incluiu um conjunto de funcionárias da SMS e SEMUR - a maioria com formação superior na área de saúde - que atuavam na área técnica das secretarias e tinham ligação com entidades e organizações vinculadas ao Movimento Negro.

Segundo o Secretário de Saúde, a criação desse GT foi decorrente da necessidade de dar curso ao compromisso estabelecido no programa de governo com a problemática da SPN. Entretanto, a fala do secretário evidencia que a criação do GT não se limitou à delegação de responsabilidades acerca da política de SPN, traduzindo-se em apoio real por parte do gestor ao seu funcionamento:

[...] na hora que o GT precisava de um espaço e que esse espaço era disputado por outro grupo, na hora que precisava de um computador, na hora que precisava articular politicamente com a Secretaria de Relaçōes Internacionais da prefeitura, outro órgão que também participou, com a SEMUR, Reparação, eu dava meu apoio (Egito).

Por conta disso, e também pelo fato de contar com o apoio do conjunto de atores não governamentais, conforme referido anteriormente, o GTSPN veio a tornarse o ator central no processo de formulação da política, iniciando seu trabalho com a sistematização das informaçōes relativas ao Observatório da Violência no Carnaval, buscando analisá-las com a inclusão do quesito raça-cor. Desse modo, deu-se visibilidade imediata à problemática racial na análise da situação de saúde da população do município, o que conferiu legitimidade ao trabalho do grupo.

Parte significativa da atuação do GTSPN incluiu a mobilização de pessoas e grupos inseridos em distintos níveis do sistema de saúde municipal, promovendo a organização de eventos, incluindo a realização de seminários de divulgação dos produtos do trabalho, a exemplo do Diagnóstico de Saúde da População Negra, a Cartilha da Mulher Negra, e os documentos gerados no âmbito do Programa de Combate ao Racismo Institucional, junto aos movimentos sociais.

Além do que ocorreu na SMS, vale destacar o que vinha acontecendo no âmbito da SEMUR, criada em 2003, que teve para sua direção a indicação de uma liderança oriunda do Movimento Negro, mais especificamente do bloco afro Ilê Aiyê, em função da forte articulação nacional pela ocupação dos espaços institucionais no período em que tinha sido criada a SEPPIR.

No governo João Henrique, a SEMUR, cujo secretário era militante do Partido dos Trabalhadores, contou com um conjunto de técnicos e quadros políticos vinculados ao Movimento Negro. Umas das entrevistadas, a coordenadora de 
articulação da SEMUR, também com história de participação no Movimento

Negro, militante do PC do B, expõe sua compreensão sobre os distintos papéis e participação, do movimento social e do estado, no processo de formulação da política. Para ela, ao primeiro caberia apresentar problemas, e ao segundo, implementar as políticas:

Hoje estou na condição de gestora e tive a oportunidade de estar coordenando a Secretaria da Reparação, que é também uma dádiva do movimento negro. Foi o resultado da luta do movimento negro porque o movimento negro entendeu que não tinha, não era responsabilidade do movimento social estar implantando políticas públicas, é dever do estado, como diz a Constituição no seu artigo V, é dever do estado fazer com que aconteça pro seu cidadão, saúde, educação e habitação. Nessa linha da Constituição de 88 nós resolvemos pautar as políticas públicas, que aí eu tive a oportunidade de coordenar a Secretaria da Reparação. (Angola)

Do ponto de vista dos atores governamentais, portanto, configurou-se uma “janela de oportunidade” para a institucionalização da política de SPN, contandose com o apoio, não só dos gestores de secretarias importantes envolvidas no processo, mas também do conjunto articulado de organizações da sociedade civil interessadas na formulação e implementação dessa política.

\section{Raça e saúde: concepçôes gerais dos atores}

Parte da caracterização dos atores diz respeito à concepção mais geral acerca da relação entre raça e saúde, que emergiu do conjunto das entrevistas realizadas. Em primeiro lugar, é importante destacar a compreensão acerca da questão racial compartilhada, em maior ou menor grau, pelo conjunto dos atores, como uma questão enraizada na sociedade brasileira, dizendo respeito às condiçôes e modos de vida da população como um todo. Para esse grupo, portanto, a problemática racial não se restringe ao biológico, expressando as desigualdades econômicas, sociais e culturais presentes nessa sociedade (Madagascar, Angola, Nova Guiné, Benin, Angola, Nigéria, Egito).

Nessa perspectiva, defendem que essa questão seja assumida como uma questão de política pública, a ser encampada por diversas organizações da sociedade civil interessadas em seu enfrentamento, e não apenas por organizações formadas por entidades e representantes do movimento negro. Chama atenção o discurso de dois atores, que abordam esse ponto específico sob duas perspectivas: uma externa ao Movimento Negro, ou seja, das organizações e instituiçōes do Estado ou sociedade civil alheias à problemática da questão racial, e outra interna ao 
movimento, as organizações da sociedade civil comprometidas e/ou organizadas em torno da questão:

[...] primeiro não se aceitava discutir isso porque racismo no Brasil 'não existia', era 'coisa do Movimento Negro'. Depois que esse argumento passou a ser indefensável, em função dos dados e dos fatos, então passou a se dizer: 'não, vai ter um organismo para tratar das questôes raciais, mas é isso aqui', 'é esse círculo aqui', 'vamos dar esse espaço', como a gente sempre diz, 'pra negrada fazer a zoada dela', certo? Mas agora a gente já está em outro patamar. Quer dizer, a gente não quer ter negros falando das questōes raciais, apenas. A gente quer negros falando das questôes de outras políticas públicas, mas com o olhar e o recorte da questão racial (Zimbábue).

[...] militantes muito 'xiitas' não permitem que pessoas não negras tomem a frente dessa questão, essa é uma coisa que enquanto mulher e negra me incomoda muito. Enquanto nós não encararmos essa questão como uma questão de todos nós, seres humanos, mulheres, homens, negros, não negros, se não dermos as mãos, nós vamos ficar fragmentados e a luta vai continuar muito frágil, muito tímida. Pra que a gente venha a avançar [...] o que a gente precisa é de uma ação conjunta (Nigéria).

Ambas as situações, tanto a que limita a intervenção do movimento no governo a secretarias, assessorias, órgãos técnicos, fóruns temáticos, etc., quanto a que "racializa" a condução do problema, não só restringem as possibilidades de ação como desencadeiam (reforçam) uma postura corporativa nos indivíduos que ocupam os espaços representativos, ou mesmo do Movimento Negro, limitando sua capacidade de articulação com outras organizações da sociedade civil que não se ocupam da questão racial.

Com relação a esse movimento, inclusive, vários dos entrevistados chamam a atenção para sua complexidade e heterogeneidade interna no que diz respeito a posições e formas de encaminhamento das questôes. Um dos entrevistados, destacada liderança desse movimento, expressa de forma bastante clara essa visão:

Não existe um movimento negro, existem movimentos negros. A temática racial é trabalhada com diversos atores, [...] vários atores nesse processo todo foram se construindo, se constituindo enquanto elementos que, quando você olha, é como se fossem uma grande onda, uma grande onda preta, vindo desembocar na praia. (Gana)

Assim, o conjunto de atores que participaram do processo de formulação da PSPN em Salvador apresenta consonância com setores do Movimento Negro filiados ao debate da Promoção de Igualdade Racial, envolvidos com o "pré e pós-Durban”. Esses setores se caracterizam por adotarem ações mais propositivas, passando a se mobilizar, na década de 90, em torno da construção 
de políticas públicas em áreas até então trabalhadas de forma genérica pelo próprio movimento, como é o caso da saúde.

\section{Proposições e ações dos atores no contexto de formulação da PSPN}

O processo de formulação da PSPN em Salvador fez parte da elaboração do Plano Municipal de Saúde 2006-2009, iniciado no primeiro ano da gestão, em 2005. Esse processo contemplou a realização de um conjunto de momentos que implicaram a realização de oficinas de trabalho no âmbito dos Distritos Sanitários e no nível central da SMS.

Desse modo, o trabalho do GTSPN confluiu para a elaboração dos produtos parciais que foram sendo incorporados ao Plano Municipal. Um primeiro produto foi o Diagnóstico de Saúde da População Negra (SMS, 2006), cuja elaboração correspondeu ao momento de "pré-decisão", no qual ocorreu o levantamento dos problemas que foram ponto de partida para a formalização de propostas de intervenção, algumas das quais já vinham sendo implantadas no sistema municipal de saúde por indução de atores externos, como foi o caso do Programa de Atenção a Pessoas com Anemia Falciforme (induzido pelo MS) e o Programa de Combate ao Racismo Institucional (SEPPIR e SEMUR).

\section{Participação dos atores no momento de "pré-decisão"}

Os atores, ao se referirem aos problemas de saúde da população negra em Salvador, destacam a questão das desigualdades sociais como determinantes das condiçõos de saúde da população afrodescendente. Isso está evidente ao relatarem problemas específicos, a exemplo da anemia falciforme, os agravos provocados pela violência social, principalmente na periferia da cidade - já apresentada no documento Rastros da Violência, elaborado pelo Fórum Comunitário de Combate à Violência -, e as doenças sexualmente transmissíveis, identificados por outros representantes do Movimento Negro, conforme trechos abaixo:

Nos terreiros de candomblé se falava muito acerca da saúde da população negra, [...] tínhamos notícias de muitas pessoas da nossa comunidade, do próprio Ilê Aiyê, dos terreiros de candomblé, que morriam de anemia falciforme (Nigéria).

A gente foi coletar dados no IML sobre mortalidades por violência desde 1997. E, observamos que, quando fazíamos a estratificação por raça-cor, [...] os negros, os pardos e os pretos, eram [os grupos] onde mais a mortalidade incidia. E quando 
cruzávamos (esses dados) com dados socioeconômicos coletados do IBGE também, confirmávamos aquilo que a gente tinha lido nos textos nacionais, etc. (Nova Guiné).

$\mathrm{Na}$ UNEGRO, nós fizemos o primeiro projeto de saúde da população negra pautado nas doenças sexualmente transmissíveis [com ênfase na população] do Pelourinho. E nós fomos muito criticados por isso. 'Só o negro morre de AIDS?' Não, isso não é possível! E a gente mostrou pela estatística, em parceria com alguns setores da Universidade Federal da Bahia, que em Salvador havia um índice alto de população negra contaminada com o vírus HIV (Angola).

Além desses problemas, aparece na fala de vários entrevistados (Zimbábue, Congo, Angola, Gana, Madagascar, Nigéria) a problemática do racismo institucional referido como problema que afeta a saúde da população negra e se expressa nitidamente nas relações estabelecidas entre os usuários do sistema público de saúde e os profissionais e trabalhadores desse setor. Também é feita uma menção ao preconceito com a existência de outras concepções de saúde, a exemplo das praticadas nos terreiros de candomblé (Benin).

Alguns dos problemas apontados pelos entrevistados foram incorporados ao conjunto de problemas identificados pelo grupo técnico responsável pela Análise da Situação de Saúde, capítulo do PMS 2006-2009 (PMS, 2006). Além da anemia falciforme e da violência, problemas priorizados no PMS, também foi dado destaque à alta taxa de mortalidade materna e infantil, problema não valorizado explicitamente pelos atores entrevistados, embora represente, ainda, uma grande preocupação para os gestores do SUS em todo o país, inclusive na Bahia e em Salvador (PMS, 2006).

Foi incluído também como prioridade o racismo institucional, problema valorizado no contexto da assinatura do convênio entre a SMS, SEMUR e o DEFID (Department for Internanational Development of United Kingdom) para a implantação do Programa de Combate ao Racismo Institucional nos serviços da rede da SMS (Zimbábue). Também foi incluído como problema o "conflito de racionalidades em saúde", que reflete o esforço da SMS para o reconhecimento dos espaços religiosos de matriz africana como locais de educação e promoção em saúde, prevenção e tratamento de doenças (PMS, 2006).

\section{Participação dos atores no momento de "decisão"}

O momento da "decisão" corresponde à formalização da política de SPN no município, isto é, à elaboração do Módulo Operacional 7 do Plano Municipal 
de Saúde, inteiramente dedicado aos problemas específicos da população negra, visto que os problemas comuns a outros segmentos da população do município foram distribuídos nos demais módulos (PMS, 2006).

Uma primeira questão diz respeito à pertinência de se criar um módulo específico dedicado à problemática da SPN. Segundo o secretário municipal de saúde da época:

Quando nós decidimos fazer um plano municipal de saúde, 2006-2009, fizemos um módulo, uma linha, um eixo específico para a Saúde da População Negra, e encontramos resistência dos técnicos, 'não, saúde da população negra, é saúde da população pobre de modo geral, a população toda de Salvador é $80 \%$ negra, não tem sentido!'. Ainda que esse seja um argumento com certa consistência do ponto de vista técnico, acho que do ponto de vista político foi correto reforçar um módulo especifico dentro do plano municipal, o que legitima a política, legitima o grupo... (Egito)

Nessa perspectiva, o GTSPN assumiu a coordenação do debate das questões relativas a esse segmento, no qual foram incorporados vários dos atores referidos anteriormente. Cabe destacar a participação dos representantes da ABDFAL, do Fórum Comunitário de Combate à Violência e da Rede Nacional de Religióes Afro-Brasileiras de Saúde, que explicitaram muitas das propostas que vinham sendo elaboradas no seio do movimento.

Com relação à anemia falciforme, o coordenador da ABDFAL explicita a importância da participação da entidade em uma câmara técnica responsável pela implementação das ações no município, comentando que a inclusão da ABDFAL mudou a forma de condução do programa, que passou, inclusive a ser coordenado por uma profissional vinculada à entidade.

Nós apresentamos o projeto que tinha sido elaborado na ABDFAL com ideias acerca da implementação do Programa de Anemia Falciforme no município. [...] [F]oi aceito e regulamentado, por isso passamos a participar de uma câmara técnica municipal, que tem como função formular as políticas, dar encaminhamento, fazer o debate, envolver outras instituições como a Fundação Osvaldo Cruz, a APAE, o HEMOBA. (Gana)

No que diz respeito ao combate à violência, o representante do Fórum Comunitário deixa claro quais foram os espaços em que se deu sua participação, denunciando a existência do problema de modo a chamar a atenção das autoridades para a necessidade de enfrentá-lo:

[...] a gente participava, participou do Conselho Municipal de Saúde, Conselho Estadual. Todos os grandes eventos e seminários que ocorreram em Salvador nesse período, a gente tinha uma presença; houve inclusive audiências públicas na Câmara de Verea- 
Quanto à participação da Rede Nacional de Religiōes Afro-brasileiras de Saúde, um dos seus representantes comenta a identificação dos problemas, a elaboração de projetos e realização de seminários sobre saúde nos terreiros, chamando a atenção que os terreiros de candomblé são espaços de resistência da cultura negra, e também o lugar onde parcela significativa da população da periferia de Salvador vai buscar ajuda, inclusive no que diz respeito a problemas de saúde. Segundo ele, a participação no Conselho Municipal de Saúde e nas oficinas do PMS gerou a proposta de humanização do atendimento ao "povo de santo" e o reconhecimento dos terreiros enquanto espaços promotores de saúde.

O que é que essa rede faz? A que ela se propõe? A humanizar o atendimento das populações de terreiros, que na sua grande maioria é uma população negra, para ter um atendimento mais humanizado no Sistema Único de Saúde (SUS)... (Benin)

A sistematização do conjunto das propostas apresentadas foi feita pelo GTSPN, resultando na incorporação das propostas nos vários módulos do plano: as açōes de promoção e vigilância da saúde (módulo 1), as ações de atenção básica e de média complexidade (módulos 2 e 3 ) aos agravos que incidem especificamente sobre essa população, e o desenvolvimento de recursos humanos (módulo 5) e melhoria do controle social (módulo 6), tratando de incluir propostas de ação que incidam sobre as deficiências do sistema com relação ao atendimento das necessidades da população negra.

O módulo operacional correspondente à Política de Saúde da População Negra incluiu as linhas de ação que o GTSPN considerou que deveriam ficar sob sua responsabilidade direta, ainda que envolvessem outros órgãos da SMS e outras instituições governamentais e não governamentais em sua operacionalização. Ficaram, portanto, sob responsabilidade do GT as seguintes ações estratégicas: a) Montagem da rede de informação para o monitoramento dos agravos prevalentes na população negra de Salvador; b) Implantação do Observatório da Saúde da População Negra de Salvador; c) Implementação das ações de combate ao racismo institucional na saúde; d) Formação da rede municipal de centros religiosos de matriz africana que desenvolvem atividades de saúde; e) Desenvolvimento de ações de saúde nas áreas remanescentes de quilombos urbanos (PMS, 2006). 
Chama a atenção a inclusão da problemática dos quilombos urbanos em Salvador, que não havia sido identificada durante a fase de elaboração do Diagnóstico de Saúde da População Negra, em 2005. Cabe registrar, entretanto, que por essa época, o Governo Federal passou a conceder importância à persistência de populações "quilombolas", sendo que o Ministério da Saúde incorporou o tema em sua agenda estratégica, o que veio a repercutir no processo de elaboração da Política Municipal de Saúde em Salvador (TEIXEIRA, 2009).

Finalmente, cabe registrar que as linhas de ação que incorporam propostas apresentadas pelos atores não governamentais são, basicamente, as relativas à assistência a pessoas com doença falciforme e às ações de prevenção e controle dos agravos relacionados à violência, inclusive aquela praticada contra a mulher negra. Também aparece no PMS, especificamente no módulo específico da PSPN, as propostas relativas à "humanização do atendimento" à população afrodescendente nas unidades de saúde, citadas em entrevistas (Benin, Gana, Nigéria, Angola, Madagascar, Congo) enfatizando-se a necessidade de respeito às crenças e tradições vinculadas à religião de matriz africana, o que reflete o papel desempenhado pela Rede Nacional de Religiōes Afro-brasileiras de Saúde (Benin).

\section{Comentários finais}

O contexto político institucional no período estudado configurou uma "janela de oportunidade" para que um conjunto heterogêneo de atores, que tinham em comum a mobilização em torno da problemática da saúde da população negra, se articulasse no âmbito da SMS. Muitos destes transitaram, ao longo de sua atuação, entre os espaços governamentais e não governamentais, o que reflete, inclusive, certa capacidade de mobilização e pressão política por parte das organizações da sociedade civil sobre a burocracia estatal, influenciando o trabalho dos técnicos e consultores da política, bem como as decisões dos gestores e coordenadores de programas e projetos.

Assim, os atores envolvidos conseguiram dar visibilidade a problemas historicamente negligenciados e incluí-los na agenda política da saúde. Tornouse possível, então, a elaboração de propostas de intervenção que valorizem o recorte racial na produção de conhecimentos acerca da situação de saúde de uma população, como a soteropolitana, composta em sua imensa maioria 
por afrodescendentes, orientando ações dirigidas ao enfrentamento dos determinantes sociais e dos efeitos clínico-epidemiológicos dos problemas de saúde da população negra no município.

Com isso, fica evidenciado que as características desse processo de formulação, bem como os seus produtos iniciais, conservam a marca da influência e o poder de pressão das organizações do movimento negro, demonstrando que a análise da formulação de uma política de saúde passa não só pela compreensão dos contextos, mas, necessariamente, dos atores, sua origem, seu processo de constituição e motivações ao longo do processo. ${ }^{1}$

\section{Referências}

BARATA, R. B. Como e porque as desigualdades sociais fazem mal à saúde. Rio de Janeiro: Fiocruz, 2009.

BARDIN, L. Análise do Conteúdo. Lisboa: Edições 70, 1977.

BENTES, N. Brasil-Durban-Brasil: um marco na luta contra o racismo. Revista Estudos Feministas. v.10, n.1, p. 229-236, 2002

BRASIL. Ministério da Saúde. 12a Conferência Nacional de Saúde. Conferência Sérgio Arouca. Relatório final. Brasília: MS, 2005.

BRASIL. Senado Federal. Constituição da República Federativa do Brasil. Brasília: Senado Federal, 1988.

CAPELA, A.C.N. Perspectivas teóricas sobre o Processo de Formulação de Políticas Públicas. In: HOCHMAN, G.; ARRETCHE, M.; MARQUES, E. Políticas Públicas no Brasil. Rio de Janeiro: Fiocruz, 2007, p.87-121.

CARNEIRO, S. A batalha de Durban. Revista Estudos Femininos. Florianópolis, v.10, n.1, p.209-214, 2002 .

DEBERT, G.G. A reinvenção da velhice: Socialização e processos de reprivatização do envelhecimento. São Paulo: FAPESP, 2004.

DOMIGUES, P. Movimento Negro: alguns apontamentos históricos. Revista Tempo, v.12, n.23, p. 100-122, 2007

FRY, P.H. O significado da anemia falciforme no contexto da "política racial" do governo Brasileiro 1995-2004. História, Ciências, Saúde-Manguinhos. Rio de Janeiro, v. 12, n. 2, p. 374-70, 2005.

LIMA, T.; FONSECA, C.M.O.; HOCHMAN, G. A saúde na construção do Estado Nacional no Brasil: Reforma Sanitária em Perspectiva Histórica. In: LIMA, N.T. et al. (org.). Saúde e Democracia: História e Perspectiva do SUS. Rio de Janeiro: Fiocrus, 2005. p. 27-58. 
GERSCHMANN, S. A formulação de Políticas Sociais. In: TEIXEIRA, S.F. (org). Reforma Sanitária em busca de uma teoria. São Paulo: Cortês, 1989. p. 119-134.

GODINHO, L.O. Normas e redistribuição: um estudo sobre condicionantes internacionais das políticas de combate ao racismo no Brasil. Revista. Brasileira de Política Internacional. v. 52 , n.1, p. 71-88,2009.

GOHN, M.G. Teorias dos Movimentos Sociais: paradigmas clássicos e contemporâneos. São Paulo: Loyola, 1997.

GONÇALVES, L.A. Os movimentos negros no Brasil: construindo atores sociopolíticos. Revista Brasileira de Educação, n.9, p.30-50, 1998.

GUimarÃES, A.S.A. Classes, Raças e Democracia. São Paulo: Editora 34, 2002. . A questão racial na política brasileira (os últimos quinze anos). Tempo Social: Revista de Sociologia da USP. São Paulo, v.13, n.2, p.121-142, 2001.

HERINGER, R. Mapeamento de ações e discursos de combate às desigualdades raciais no Brasil Estudos Afro-Asiáticos, v.23, n.2, p.1-43, 2001.

JACCOUD, L.B., BEGHIN, N. Desigualdades raciais no Brasil: um balanço da intervenção governamental. Brasília: IPEA, 2002.

KINGDON, J.W. Agenda, Alternatives and Public Policies. $2^{\circ}$ ed. New Yors: Harper-Collins College, 1995.

LINDBLOM, C.E. O processo de decisão política. Brasília: UnB, 1985.

MUNANGA, K. História do Negro no Brasil: o negro na sociedade brasileira: resistência, participação e contribuição. Brasília: Fundação Cultural Palmares, 2004.

NOGUEIRA, J.C. Movimento Negro: das práticas de denúncia ás políticas públicas. Politica e Sociedade, n. 5, p.89-99, 2004. . (org.). História do trabalho e dos trabalhadores negros no Brasil. São Paulo: CUT, 2001.

OLIVEIRA, M.F. As síndromes Falciformes e o PAF/MS. In: WERNECK, J.; MENDONÇA, M.; WHITE, E.C. (org.). O livro da saúde das mulheres negras: nossos passos vêm de longe. Rio de Janeiro. Pallas, 2000.

OLIVEIRA, G.C.; SANT'ANA, W. Chega de Saudade, a realidade é que... Revista de Estudos Feministas, v.10, n.1, p 199-207, 2002.

PAIM, J.S. Reforma Sanitária Brasileira: contribuição para compreensão e crítica. Salvador: EDUFBA, 2008.

Abordagens teórico-conceituais em estudos de condições de vida e saúde: notas para reflexão e ação. In: BARATA, R.B. (org.). Condiçôes de vida e situação de saúde. Rio de Janeiro. ABRASCO, 1997. p. 7-30.

PIOVENSAN, F. Ações afirmativas no Brasil: desafios e perspectivas. Estudos Feministas, Florianópolis, v.16, n.3, p.887-896, 2008. 
ORGANIZAÇÃO PANAMERICANA DA SAÚdE. Seminário Política Nacional de Saúde da População Negra: uma questão de equidade, Brasília: OPAS, 2001.

PREFEITURA MUNICIPAL DE SALVADOR. Secretaria Municipal de Saúde. Plano Municipal de Saúde 2006-2009. Salvador: SMS, 2006.

RABELO, S.H.S. A igualdade em construção: políticas de ação afirmativa para inclusão de negros no ensino superior público brasileiro Revista de Estudos e Pesquisa em Educação, v.10, p.87-98, 2008.

SECRETARIA MUNICIPAL DE SAÚDE DE SALVADOR. Diagnóstico de Saúde da População Negra de Salvador. Salvador, 2006.

- Assessoria de Promoção da Equidade Racial em Saúde. Religiões de Matriz Africana. SMS. Salvador. Cartilha Quilombola, n. 2, maio 2008.

TANNUS, L.; GOULART, F. Subsidios para o enfrentamento do racismo na saúde. Brasília, maio 2007.

TEIXEIRA, C.F. et al. O processo de formulação da Política de Saúde da população negra em Salvador, 2005-2006. Relatório de pesquisa. Salvador: ISC-UFBA, 2009.

TESTA M. Pensamento estratégico e lógica de programação: o caso da saúde. São Paulo: Hucitec, 1995.

\section{Nota}

${ }^{1}$ M.V.R. de Araújo foi responsável pela elaboração e redação da introdução, revisão bibliográfica, quadro teórico, análise e redação dos resultados. C.F. Teixeira colaborou com a revisão do artigo, organização do quadro teórico e com as considerações finais do manuscrito. 


\section{Abstract}

Participation of actors in the formulation of health policies for the black population in the city of Salvador, Brazil

This paper aims to characterize the actors and analyze their participation in the formulation of Health Policies for the Black Population (PSPN) in the city of Salvador, Brazil, between 2005 and 2006. Document review and interviews with key informants and representatives of governmental and non-governmental organizations involved in the process were performed. The results describe the characteristics of the actors and analyze their ties to organizations and trajectories in the Black Movement. Then it discusses the forms of actors' participation in the pre-decision and the decision regarding the PSPN, preparing the Municipal Health Plan 2006-2009 process. We conclude that the institutional political context during the study period set a "window of opportunity" for a heterogeneous set of actors, who shared the mobilization around the issue of health of the black population, articulated within the municipal health secretariat and included the issue on the political agenda in any municipality which largely delineated the characteristics of this process and its products.

> Key words: political actors; formulation of policies; health of the black population. 